${ }^{\bullet}$ Entomologica Fennica. 8 May 2000

\title{
A new and little known species of the genus Aspistes Meigen(Diptera, Scatopsidae) from Finland
}

\author{
Nina P. Krivosheina
}

Krivosheina, N. P. 2000: A new and little known species of the genus Aspistes Meig. (Diptera, Scatopsidae) from Finland. - Entomol. Fennica 11: 119-123.

Flies of the genus Aspistes Meigen from the collection of the Zoological Museum, University of Helsinki, Finland, $(\mathrm{ZMH})$ have been revised. One new species, A. helleni sp.n., is described from Finland. Data on the morphology and the distribution of $A$. freyi Cook are given, including the description of the female. A key to the Palaearctic species of the genus Aspistes Meigen is presented.

Nina P. Krivosheina, A.N. Severtzov Institute of Ecology and Evolution, Russian Academy of Sciences, 33 Leninsky Prospect, 117071 Moscow, Russia

Received 3 July 1998, accepted 7 October 1999

Two species of the genus Aspistes Meigen, 1818, are previously known: A. berolinensis Meigen, 1818 , and A. freyi Cook, 1965. A revision of the collection kept in the Zoological Museum in Helsinki resulted in the discovery of one more new species, closely related to $A$. freyi Cook. Key to the Palaearctic species of the genus Aspistes Meigen.

1. With paired appendages (gonostyli) of variable form present behind sternite VIII (Figs. 3,14) (Males) 2

- No appendages behind sternite VIII; sternite VIII sometimes with projections of variable form (Figs. 4,12) (Females) 4

2. Antennae 12-segmented. Gonostyli pointed (Fig. 7); sternite VIII seemingly medially divided, each part elongated and pointed, longer than wide. Frons and the median part of occiput roughly sculptured; frontal and facial hairs short and rare. Frons almost as wide as the distance between lateral ocelli (Fig. 8).
2,25-2,50. - Widely distributed in Europe, including the European part of Russia.

A. berolinensis Meigen

- Antennae 10-segmented. Gonostyli massive, widely rounded apically (Figs. 2,3,13,14) . 3

3. Frons about as wide as the distance between the bases of the antennae (Fig. 9). Gonostyli with massive strongly sclerotized projection in base, twice as long as wide; the rest part of the gonostyli a little transverse (Figs. 13,14). 2,0-3,0. - Finland, Latvia ........ A. freyi Cook

- Frons in its narrow part in front of antennae as wide as the diameter of the median ocellus (Fig. 1). Gonostyli with short basal sclerotized projection, as long as wide; the rest part of gonostyli elongated (Figs. 2,3). - 3,0-3,5. Finland A. helleni sp.n.

4. Sternite VIII widely rounded posteriorly, with small flat concavity in the middle (Fig.16). Spermatheca oval (Fig. 15).

Frons wider than the distance between the bases of antennae (Fig. 17)

A. berolinensis Meig. 


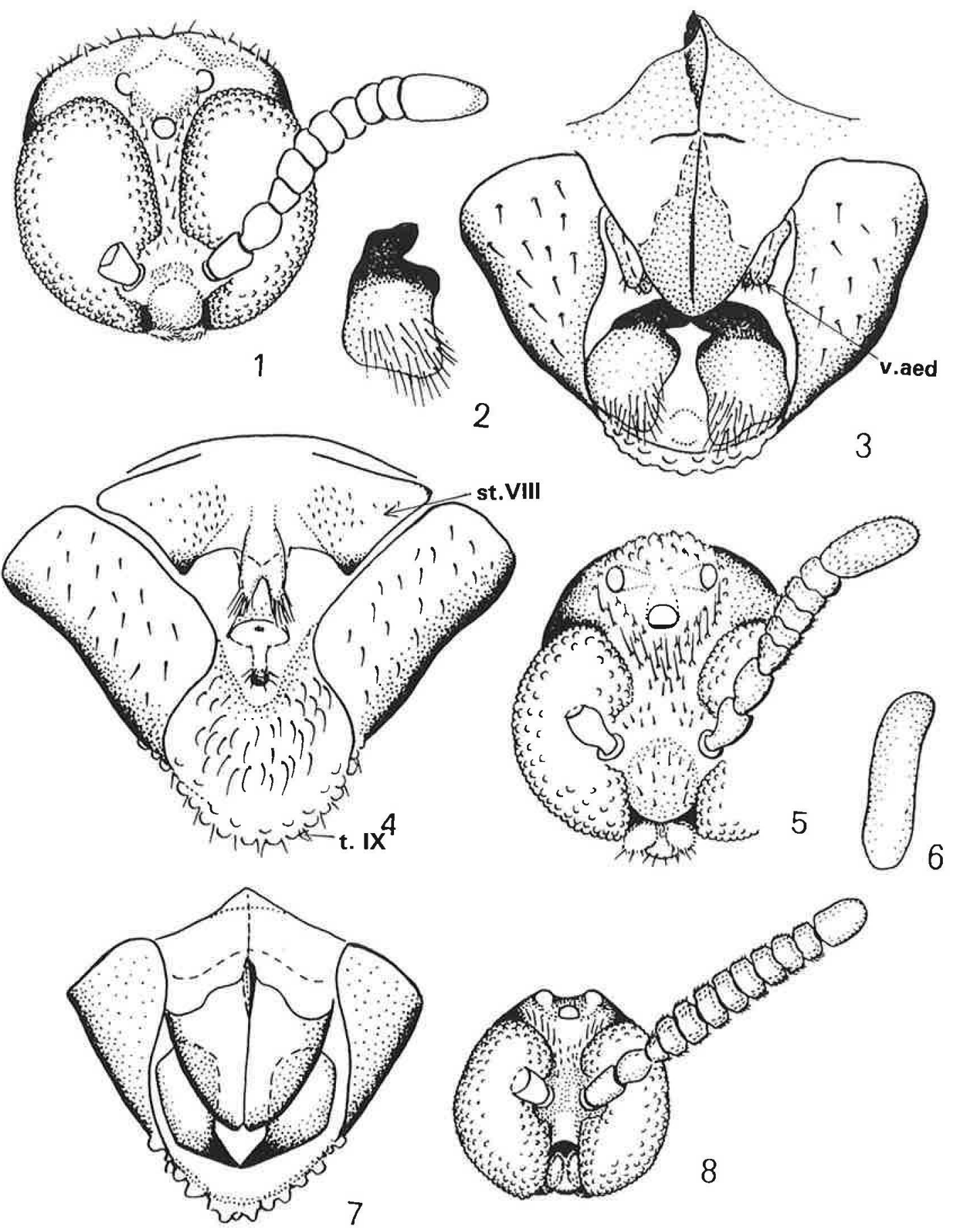

Figs.1-8. Aspistes helleni, sp.n. (1-6) and A. berolinensis Meig.(7-8). 1. head of male, anterior view; 2. gonostyle; 3. male terminalia, ventral view; 4 . female terminalia, ventral view; 5 . head of female, anterior view; 6 . spermatheca; 7 . male terminalia, ventral view; 8 . head of male, anterior view. Abbreviations: st.VIII - sternite VIII; v.aed. - valves of aedeagus; $\mathrm{t} I \mathrm{X}$ - tergite IX. 

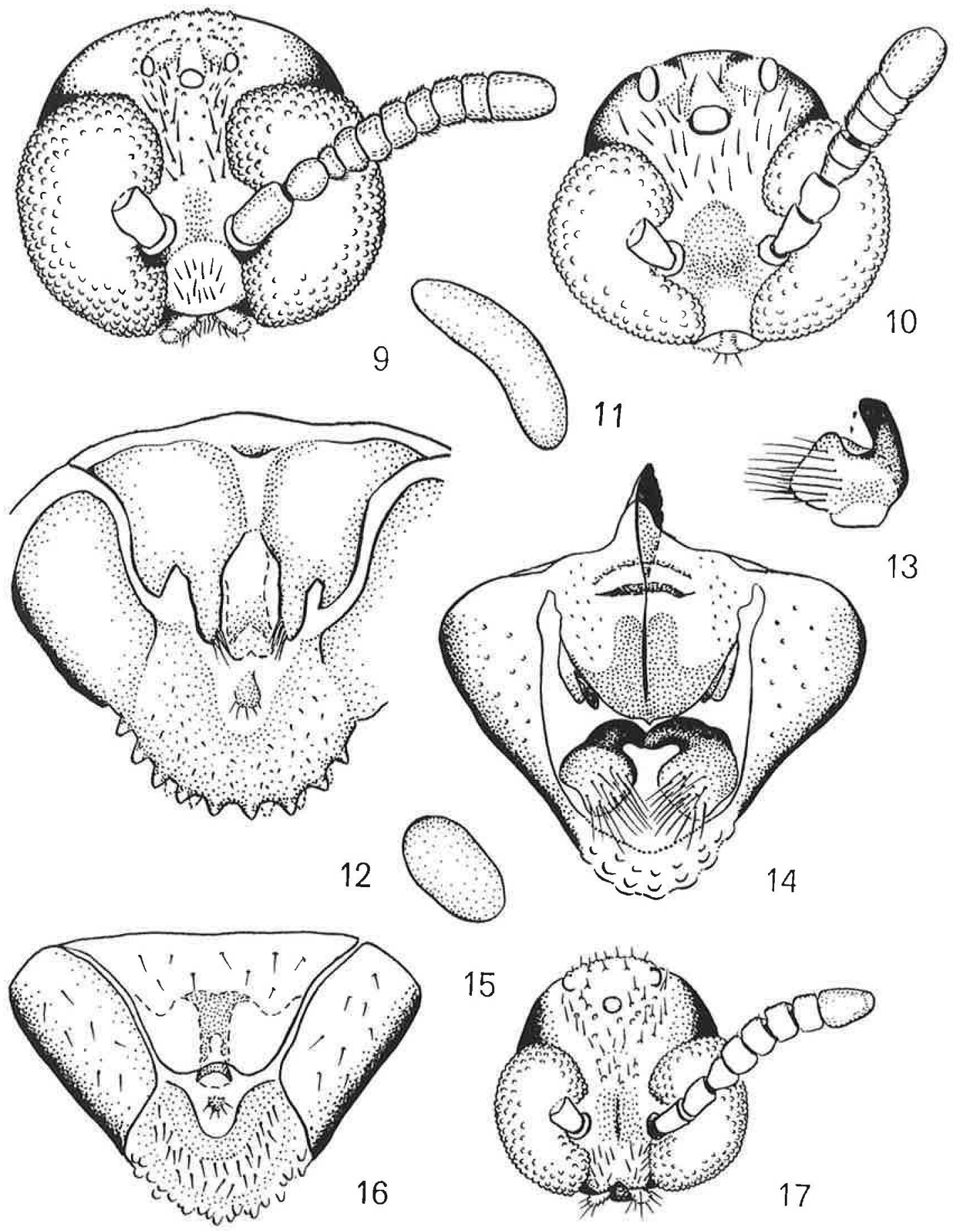

Figs. 9-17. Aspistes freyi Cook (9-14) and Aspistes berolinensis Meigen(15-17). 9. head of male, anterior view; 10. head of female, anterior view; 11. spermatheca; 12. female terminalia, ventral view; 13. gonostyle; 14 . male terminalia, ventral view; 15. spermatheca; 16. female terminalia, ventral view; 17. head of female, anterior view. 
- Sternite VIII with paired posterior projections (Figs. 4, 12). Spermatheca elongated (Figs. 6, 11) 5

5. Sternite VIII with two separate median projections (Fig. 12) A. freyi Cook

- Sternite VIII with one bilobate median projection (Fig. 4) A. helleni sp.n.

\section{Aspistes helleni, sp.n. Figs. 1-6}

Type locality: Finland: Tytärsaari.

Holotype: $\sigma^{x}$, Finland: Tytärsaari. without date, Hellen (ZMH), Type number 756.

Paratype: $\sigma^{*}, q$, the same data (ZMH, N 1056 of, N 791 \%); \$, Finland: Seiskari. Hellen (ZMH, N 1590, क).

Description of male. Male (Figs. 1-3). Body black. Head (Fig. 1). Eyes very close; frons slightly narrowing towards bases of antennae, minimum width equal to diameter of median ocellus; frons and the median portion of occiput microsculptured; frons and face with relatively dense erect hairs. Ocellar triangle projecting above eyes; lateral ocelli at level of posterior margins of eyes. Face convex with a few short erect hairs. Antennae 10-segmented. Disc (U-shaped elevatedshield) and the rest part of mesonotum with short straight uniform non-erect light hairs. Coxae and femora black, tibia and tarsi red. Halteres black. Terminalia (Figs. 2-3). Sternite VIII cone-like, apically widely rounded; gonostyli massive, long, posteriorly with slightly elongated internal angle. Sternite IX like narrow band with small tubercles and short setae. Valves of aedeagus paired with setae.

Description of female (Figs. 4-6). Head ( Fig. 5 ). Eyes relatively widely separated, minimal distance between eyes equal to distance between antennae. Upper part of frons twice as wide as narrowest part. Median ocellus at level of upper margin of eyes. Frons roughly sculptured with long light hairs; the median portion of occiput with shorter hairs; occiput along the margin of eye bare, shining, posteriorly with hairs. Oval face projecting beyond eyes (lateral view). Antennae 8-segmented. Light hairs, covering mesonotum, slightly longer anteriorly and on disc. Tarsi brownish, bases of metatarsi lighter. Terminalia (Fig. 4). Sternite VIII with cone-like strongly sclerotized lateral projections and paired median pubescent lobes. Sternite IX massive, with dense pubes- cence. Posterior margin of tergite IX with well developed tubercles. Spermathecae elongated (Fig. 6). Other characters as in male.

\section{Body length. $3.0-3,5 \mathrm{~mm}$.}

By the genital structure the species is close to the North American species A. antydactylatis Cook, 1965, described from Canada (Goose Bay, Labrador) (Cook 1965). The male of the Krivosheina: New and little known specie new species however is characterized by having longer gonostyli with blunt weakly developed projection, a short sternite IX, a widely rounded sternite VIII; a 10-segmented antennae with indistinct segmentation. The female terminalia of the new species is similar to $A$. antydactylatis Cook but differing in the structure of sternite VIII.

Etymology. The species is named after W. Hellen who collected this material.

\section{Aspistes freyi Cook Figs. 9-14}

Material studied. Finland, Terijoki, Hellen, N 49, $1 \sigma^{*}$; without N $10^{*}$; N 5671 우 [ZMH].

The species was described from one male from Latvia (Liyepaya) and Finland (Tvärminne). Some additional diagnostic morphological characters for the male as well as the description of the female are given below.

Description of male. Male (Figs. 9, 13, 14). Eyes widely separated, frontal width no less than distance between bases of antennae. Antennae 10-segmented. Frons and median poztion of occiput roughly sculptured. Frons and face with long light hairs; median ocellus at level of posterior margin of eye. Occiput massive, wider than length of 1st antennal segment. Legs dark brown, bases of tibia and metatarsi lighter. Halteres black, stem without setae. Anterior part of mesonotum near postpronotum with group of light long hairs; relatively long hairs present on anterior part of disc. Terminalia (Figs. 13-14). Sternite VIII widely rounded; gonostyli almost square, massive.

Description of female (Figs. 10-12). Body dark brown. Head (Fig. 10). Eyes widely separated; frons wider than distance between antennae. Frons and median occipital sclerite roughly sculptured, with long light hairs. Face slightly projecting beyond eyes, with dense hairs. Antennae 8- 
segmented. Disc of mesonotum on anterior part with dense erect light hairs. Fore tibia red, mid and hind tibia bicolour, lighter in bases and darker apically; tarsi yellow, apical tarsomeres brownish. Terminalia (Fig. 12). Sternite VIII with 4 elongated and narrowed projections directed posteriorly. Tergite IX with small flat tubercles. Spermatheca elongated (Fig. 11).

Body length. 2,5-3 mm.

The species is characterized by shorter gonostyli, than those in A. helleni; female sternite VIII of typical form, with long projections; frons of male broad.
Acknowledgements. The author is very grateful to Prof. O. Bistrom and P.Vilkamaa, who helped in obtaining the material. The work was financially supported in part by the Russian Foundation for Fundamental Research, grant N 97 04-48098.

\section{References}

Cook, E. F. 1965: A contribution towards a monograph of the Scatopsidae. Part IX. The genera Aspistes and Arthria (Diptera, Scatopsidae: Aspistinae). - Ann. Entomol. Soc. Amer. 58(5): 713-721. 